\title{
BMJ Open Association between false positive glucose challenge test results and large- for-gestational-age infants: a retrospective cohort study
}

\author{
Satoshi Shinohara (1) , Atsuhito Amemiya, Motoi Takizawa
}

To cite: Shinohara S, Amemiya A, Takizawa M. Association between false positive glucose challenge test results and large-for-gestational-age infants: a retrospective cohort study. BMJ Open 2020;10:e034627. doi:10.1136/ bmjopen-2019-034627

- Prepublication history for this paper is available online To view these files, please visit the journal online (http://dx.doi org/10.1136/bmjopen-2019034627).

Received 28 September 2019 Revised 24 January 2020 Accepted 10 February 2020
Check for updates

(C) Author(s) (or their employer(s)) 2020. Re-use permitted under CC BY-NC. No commercial re-use. See rights and permissions. Published by BMJ.

Obstetrics and Gynecology, Kofu National Hospital, Kofu, Japan

Correspondence to

Dr Satoshi Shinohara; shinohara617@gmail.com

\section{ABSTRACT}

Objectives There is no consensus regarding a possible relation between false positive glucose challenge test (GCT) results and large-for-gestational-age (LGA) infants. This study aimed to clarify the association between false positive GCT results and LGA, after adjusting for potential confounding factors, using a large clinical dataset.

Design Retrospective cohort study.

Setting National Hospital Organisation Kofu National Hospital, which is a community hospital, between January 2012 and August 2019.

Participants Japanese women who underwent GCT between 24 and 28 weeks of gestation at the hospital were included. After excluding those with gestational diabetes mellitus, diabetes in pregnancy and multiple pregnancies, subjects were divided into a false positive GCT group ( $\geq 140 \mathrm{mg} / \mathrm{dL}$ ) and a GCT negative group ( $<140 \mathrm{mg} / \mathrm{dL}$ ). Methods Obstetric records of patients were examined. The $\chi^{2}$-test and multivariable logistic regression analysis were used to investigate the association between false positive GCT results and LGA.

Primary and secondary outcome measures Incidence of LGA and the association between false positive GCT results and LGA.

Results The mean subject age was $31.4 \pm 5.5$ years, with $43.3 \%$ nulliparity ( $n=974)$ and $2160(96.1 \%)$ term deliveries. The incidence of LGA was $9.4 \%$ (211/2248) and $11.4 \%(257 / 2248)$ of the women had false positive GCT results. False positive GCT results were significantly associated with an increased risk of LGA (OR, 1.51; $95 \% \mathrm{Cl}, 1.02$ to 2.23 ), after controlling for maternal age, prepregnancy maternal weight, maternal weight gain during pregnancy and parity.

Conclusions It appears that there is a significant association between false positive GCT results and LGA. Additional research is required to confirm these results and to investigate appropriate interventions for women with abnormal screens for gestational diabetes mellitus.

\section{INTRODUCTION}

Large-for-gestational-age (LGA), which is defined as a birth weight above the 90th centile, is associated with increased perinatal mortality and morbidity, ${ }^{1-3}$ future risk of developing obesity and insulin resistance. ${ }^{4-6}$ LGA increases the risk of shoulder
Strengths and limitations of this study

- To the best of our knowledge, this study is the first to investigate the association between false positive glucose challenge test results and largefor-gestational-age (LGA) infants born to Japanese women.

- Our study also had a larger sample size and analysed more risk factors for LGA than previous studies.

- It might be difficult to extrapolate our results to the general population because our study was conducted at a single centre.

- Data regarding history of previous LGA birth were not considered in this study, although this is a potential risk factor for LGA.

dystocia and neonatal intensive care unit admission, and maternal risks include higher caesarean section rates, postpartum haemorrhage and third-degree and fourth-degree tears. ${ }^{7-9}$ Several studies have suggested that prenatal identification of LGA and appropriate management of delivery in suspected LGA infants are effective preventive measures to prevent delivery-related perinatal morbidity. ${ }^{710}$ Therefore, identifying the causes of LGA and defining strategies to improve the early detection of LGA are important. LGA is attributed to many factors, such as maternal prepregnancy weight,${ }^{11-13}$ gestational diabetes mellitus (GDM), ${ }^{11} 1314$ excessive maternal weight gain, ${ }^{11-13}$ race, ${ }^{315}$ multiparity, ${ }^{11} 12$ and advanced maternal age. ${ }^{13} 16$ Among these factors, GDM in particular is highly associated with LGA infants. ${ }^{11} 1314$

In Japan, an initial screening test followed by the diagnostic oral glucose tolerance test (OGTT) in screen-positive women, known as the two-step approach, is used for GDM diagnosis. ${ }^{13}$ Moreover, the Japan Society of Obstetrics and Gynaecology has recommended the $50 \mathrm{~g}$ glucose challenge test (GCT) as a screening method for GDM. ${ }^{13}$ Women with 
abnormal GCT results (serum glucose levels $\geq 140 \mathrm{mg} / \mathrm{dL}$ ) subsequently undergo a $75 \mathrm{~g}$ OGTT for a definitive diagnosis. ${ }^{13}$ Previous studies have reported that women with a false positive GCT (abnormal GCT but normal OGTT) can be considered to have similar glucose metabolism to those with GDM from the point of view of adverse perinatal outcomes, even in the absence of a definitive diagnosis. ${ }^{17-19}$ However, these previous studies may have been limited by their small sample size, differences in the definition of GDM and insufficient information regarding potential confounding factors for LGA. ${ }^{17-19}$ In addition, other studies have reported conflicting results. ${ }^{20-22}$ As we have little evidence-based knowledge of how to manage women with borderline impaired glucose tolerance, there is no current recommendation for any intervention or treatment among women with a false positive GCT. Therefore, we used a relatively large sample (larger than in previous studies) of obstetric records to identify the risk factors for LGA, and the relationship between false positive GCT and LGA, in this retrospective cohort study.

\section{METHODS}

\section{Study design}

For the present retrospective cohort study, we collected and examined the obstetric records of women who delivered at the National Hospital Organization Kofu National Hospital between January 2012 and August 2019. This study included all Japanese women who underwent GCT between 24 and 28 weeks of gestation at the hospital. Women with GDM, diabetes in pregnancy, multiple pregnancies and missing data, as well as those who delivered before week 22, were excluded.

\section{Data collection}

The patients' obstetric records included age at delivery, parity, prepregnancy body mass index (BMI), weight gain during pregnancy and GCT results. Advanced maternal age ( $\geq 35$ years), multiparity, obesity in prepregnancy $\left(\right.$ BMI $\left.>25.0 \mathrm{~kg} / \mathrm{m}^{2}\right)$, male infant and excessive maternal weight gain were used as explanatory variables because they have been previously described as risk factors for LGA. ${ }^{11-16}$ The diagnosis of GDM was made if there was at least one abnormal plasma glucose value $(\geq 92,180$ and $153 \mathrm{mg} / \mathrm{dL}$ for fasting, 1-hour and 2-hour plasma glucose concentration, respectively) after a $75 \mathrm{~g}$ OGTT. ${ }^{13}$ These diagnostic criteria for GDM were recommended by the International Association of Diabetes and Pregnancy Study Groups after an extensive analysis of the Hyperglycaemia and Adverse Pregnancy Outcomes study. ${ }^{23}$ The prepregnancy BMI was calculated according to the WHO standard (body weight $(\mathrm{kg}) /$ height $\left.(\mathrm{m})^{2}\right)$. Maternal weight gain during pregnancy was calculated by subtracting the patient's prepregnancy body weight from her body weight at the last prenatal visit before delivery. Excessive maternal weight gain was defined according to prepregnancy BMI. ${ }^{13}$ If prepregnancy BMI was $<25.0 \mathrm{~kg} /$ $\mathrm{m}^{2}$, excessive weight gain was defined as $12 \mathrm{~kg}$ or more throughout the pregnancy. ${ }^{13}$ If prepregnancy BMI was $>25.0 \mathrm{~kg} / \mathrm{m}^{2}$, excessive weight gain was defined as $7 \mathrm{~kg}$ or more throughout the pregnancy. ${ }^{13}$ We defined LGA, which was the primary outcome of interest in this study, as a birth weight above the 10th percentile in each gestational week. ${ }^{24}$ When we classified women according to their GCT results, a threshold of $140 \mathrm{mg} / \mathrm{dL}$ was chosen, because the Japan Society of Obstetrics and Gynaecology recommended this value for use in screening for GDM. ${ }^{13}$ Maternal and neonatal outcomes were compared between women in the GCT false positive group $(\geq 140 \mathrm{mg} / \mathrm{dL})$ and those in the GCT negative group $(<140 \mathrm{mg} / \mathrm{dL})$.

\section{Statistical analyses}

The Mann-Whitney $\mathrm{U}$ test and $\chi^{2}$ test were performed to compare maternal and neonatal outcomes. Fisher's exact test was used when the expected frequency was $<5$. We then used a multivariable logistic regression analysis to examine the association between false positive GCT results and LGA, while controlling for the potential confounding factors. The logistic regression models were adjusted for GCT results, advanced maternal age, excessive maternal weight gain, parity, male infant and obesity in prepregnancy. All analyses were performed using Bell Curve for Excel (Social Survey Research Information Co., Tokyo, Japan) and IBM SPSS Statistics for Windows, V.25. The significance level was set at $\mathrm{p}<0.05$.

\section{Patient and public involvement}

Patients were not invited to comment on the study design and were not consulted to develop patient relevant outcomes or interpret the results.

\section{RESULTS}

During the study period, there were 2470 women who underwent GCT testing during the study period. After excluding 222 patients (missing data, $\mathrm{n}=22$; twin pregnancy, $\mathrm{n}=23$; non-Japanese, $\mathrm{n}=52$; GDM, $\mathrm{n}=125), 2248$ women were included in this study. The mean subject age was $31.4 \pm 5.5$ years, with $43.3 \%(\mathrm{n}=974)$ nulliparity, $2160(96.1 \%)$ term deliveries and $414(18.4 \%)$ caesarean deliveries. Table 1 lists the clinical characteristics of the enrolled women.

The characteristics of the GCT false positive and GCT negative groups were similar, except for greater maternal age in the GCT false positive group. The overall incidence of LGA in this study was $9.4 \%(211 / 2248)$, and $11.4 \%(257 / 2248)$ of women had false positive GCT results. Among the 2248 women, LGA was significantly more common in the false positive GCT group $(13.0 \%$ vs 8.9\%; $\mathrm{p}=0.03$; OR, $1.54 ; 95 \%$ CI, 1.05 to 2.26 ) (table 2).

In addition, advanced maternal age, excessive maternal weight gain and obesity were significantly associated with LGA (table 2). Moreover, after controlling for each variable, mutual adjustment yielded maternal age $\geq 35$, false positive GCT, excessive maternal weight gain and obesity (advanced maternal age: OR, 1.63; 95\% CI, 1.20 to 2.20; 
Table 1 Clinical characteristics according to maternal glucose challenge test (GCT) results

\begin{tabular}{lccc}
\hline & $\begin{array}{l}\text { GCT false } \\
\text { positive } \\
\mathbf{n = 2 7 6}\end{array}$ & $\begin{array}{l}\text { GCT negative } \\
\mathbf{n = 1 9 7 2}\end{array}$ & P value \\
\hline Maternal age & $32.5 \pm 5.4$ & $31.3 \pm 5.6$ & $<0.001$ \\
\hline Nulliparity & $117(42.4)$ & $857(43.5)$ & 0.74 \\
Premature delivery & $16(5.8)$ & $72(3.7)$ & 0.09 \\
\hline Caesarean section & $60(21.7)$ & $354(18.0)$ & 0.13 \\
Instrumental & $7(2.5)$ & $53(2.7)$ & 0.88 \\
delivery & & & 0.99 \\
\hline Male infant & $139(50.3)$ & $993(50.4)$ & 0.03 \\
\hline LGA & $36(13.0)$ & $175(8.9)$ & \\
\hline
\end{tabular}

Values are presented as mean \pm SD or number (\%).

LGA, large-for-gestational-age.

false positive GCT: OR, 1.51; $95 \%$ CI, 1.02 to 2.23 ; obesity: OR, 1.76; 95\% CI, 1.17 to 2.63; excessive maternal weight gain: OR, 2.62; $95 \% \mathrm{CI}, 1.95$ to 3.54 ) as independent risk factors for LGA.

\section{DISCUSSION}

In this study, we found that false positive GCT results were significantly associated with an increased risk of LGA after adjusting for the potential confounding factors in women without GDM.
A general consensus exists that birth weight is directly related to insulin sensitivity, indicating that maternal glucose metabolism plays an important role in foetal growth. ${ }^{142526}$ When maternal glycaemic control is impaired and the maternal serum glucose level is high, the glucose crosses the placenta. ${ }^{1425}{ }^{26}$ However, the maternal-derived insulin does not cross the placenta. ${ }^{14526}$ As a result, in the second trimester, the foetal pancreas, which is now capable of secreting insulin, starts to respond to hyperglycaemia and secrete insulin in an autonomous fashion regardless of glucose stimulation. ${ }^{142526}$ This combination of hyperinsulinemia (insulin being a major anabolic hormone) and hyperglycaemia (glucose being a major anabolic fuel) leads to an increase in the fat and protein stores of the fetus, resulting in LGA infants. ${ }^{14}$ It can be presumed that abnormal GCT is an early form of glucose intolerance. In other words, women with a positive GCT, but without a diagnosis of GDM, have mild glucose intolerance, which is similar to that of women diagnosed with GDM. Considering the mechanism of maternal glucose metabolism, it seems reasonable to speculate that false positive GCT results in women are significantly associated with LGA infants. Therefore, obese women tend to develop GDM, and blood glucose control is more difficult.

Although previous studies had slight differences in the definitions of GDM, GCT cut-offs and study population, several have reported an association between false positive GCT results and LGA infants. ${ }^{17-19}$ The current study's findings are consistent with these previous findings.

Table 2 Crude and adjusted ORs of maternal risk factors for the delivery of large-for-gestational-age (LGA) infant

\begin{tabular}{|c|c|c|c|c|c|c|}
\hline Variable & LGA, (n) & Non-LGA, (n) & $\begin{array}{l}\text { Crude } \\
\text { OR }\end{array}$ & $95 \% \mathrm{Cl}$ & $\begin{array}{l}\text { Adjusted } \\
\text { OR }\end{array}$ & $95 \% \mathrm{Cl}$ \\
\hline \multicolumn{7}{|l|}{ GCT } \\
\hline$\geq 140$ & 36 & 240 & 1.54 & 1.05 to 2.26 & 1.51 & 1.02 to 2.23 \\
\hline \multicolumn{7}{|c|}{ Maternal age } \\
\hline$\geq 35$ & 83 & 609 & 1.52 & 1.14 to 2.04 & 1.63 & 1.20 to 2.20 \\
\hline \multicolumn{7}{|c|}{ Excessive weight gain } \\
\hline No & 84 & 1292 & 1 & Reference & 1 & Reference \\
\hline Yes & 127 & 745 & 2.62 & 1.96 to 3.50 & 2.62 & 1.95 to 3.54 \\
\hline \multicolumn{7}{|c|}{ Male infant } \\
\hline No & 93 & 881 & 1 & Reference & 1 & Reference \\
\hline Yes & 118 & 1156 & 0.96 & 0.73 to 1.29 & 0.94 & 0.70 to 1.26 \\
\hline \multicolumn{7}{|l|}{ Obesity } \\
\hline No & 175 & 1861 & 1 & Reference & 1 & Reference \\
\hline Yes & 36 & 176 & 2.18 & 1.47 to 3.21 & 1.76 & 1.17 to 2.63 \\
\hline
\end{tabular}

GCT, glucose challenge test result. 
However, our study analysed more risk factors for LGA with a relatively large sample size in Japanese women. Although it is well known that glucose metabolism varies by race, ${ }^{315}$ to the best of our knowledge, this study is the first to investigate the association between false positive GCT results and LGA infants in Japanese women. In contrast, Boriboonhirunsarn et al failed to demonstrate an association between false positive GCT results and LGA. This discrepancy is likely related to their relatively small sample size $(\mathrm{n}=480){ }^{22}$

Typically, ultrasonography is known to be less accurate with increasing foetal weight and at later gestational ages. ${ }^{27-30}$ Previous literature on ultrasonography in women with diabetes focused on the detection of LGA, with most studies showing that ultrasonography performs relatively poorly in accurately detecting LGA. ${ }^{29}$ Moreover, a recent prospective cohort study reported that a combination of foetal parameters, biochemical indices and maternal demographics was not shown to be predictive for LGA infants. ${ }^{31}$ In contrast, if the $50 \mathrm{~g}$ GCT at second trimester may also provide diagnostic information regarding LGA, this method is useful because it is already widely used for GDM screening in Japan. Therefore, no additional costs or patient examinations would be necessary.

Maternal obesity and excessive maternal weight gain are also significantly associated with LGA. ${ }^{11-13}$ Several studies have reported that maternal obesity and excessive maternal weight gain itself are among the most important risk factors for LGA. ${ }^{11-13}$ Both maternal obesity and excessive maternal weight gain cause low maternal insulin sensitivity, which is thought to be a cause of LGA. ${ }^{32}$ Therefore, more attention should be paid to women with false positive GCT results if they are obese or have excessive weight gain during pregnancy. In this study, women with false positive GCT results and obese status delivered LGA infants in 8/37 (21.6\%) cases (data not shown). Obese individuals are typically less insulin sensitive than the normal-weight population. ${ }^{33}$ Therefore, the blood glucose level is likely to be higher in obese women than in the normal-weight population. Therefore, it is not surprising that women with false positive GCT results and obese status delivered LGA infants as frequently as about 20\%. Recently, Ensenauer et al reported that HbA1c is useful as a marker for late dysglycaemia in the last trimester in obese pregnant women after exclusion of gestational diabetes. ${ }^{34}$ Accurate risk stratification using HbA1c analysis also could assist in the management of women with false positive GCT results in the Japanese population. Furthermore, women with false positive GCT results and excessive weight gain delivered LGA infants in $19(19.8 \%)$ cases (data not shown).

Our study has several limitations. First, it might be difficult to extrapolate our results to the general population because our study was conducted at a single centre. Therefore, a large-scale, multicentre, cohort study is needed to confirm these results in the general population.

Second, data regarding history of previous LGA birth ${ }^{35}$ were not considered in this study, although this is a potential risk factor for LGA. Third, the generalisability of our findings may be limited by the homogeneity of this cohort, which contained only Japanese women.

Despite these limitations, our study's strengths include its design and number of participants. Our study also had a larger sample size and analysed more risk factors for LGA than previous studies. ${ }^{17-22}$

In conclusion, we found that false positive GCT results are significantly associated with LGA.

GDM occurs on a continuum with no easily specified, discrete points at which to distinguish normal from abnormal. Additional research is required to confirm these results and to determine appropriate interventions for women with abnormal screens for GDM.

Acknowledgements We thank the study participants for permitting us to use their personal data.

Contributors SS, MT: data collection. SS: conception or design of the work. SS, AA and MT: data analysis and interpretation; critical revision of the article. SS, AA and MT: drafting of the article and final approval of the version to be published.

Funding The authors have not declared a specific grant for this research from any funding agency in the public, commercial or not-for-profit sectors.

Competing interests None declared.

Patient consent for publication Not required.

Ethics approval The Human Subjects Review Committee of the National Hospital Organization Kofu National Hospital reviewed and approved the study protocol and waived the need for informed consent because of the retrospective study design. However, patients were provided the opportunity to refuse the usage of their data through the hospital's website. All procedures were performed in accordance with the 1964 Helsinki Declaration and its later amendments.

Provenance and peer review Not commissioned; externally peer reviewed.

Data availability statement All data relevant to the study are included in the article or uploaded as supplementary information.

Open access This is an open access article distributed in accordance with the Creative Commons Attribution Non Commercial (CC BY-NC 4.0) license, which permits others to distribute, remix, adapt, build upon this work non-commercially, and license their derivative works on different terms, provided the original work is properly cited, appropriate credit is given, any changes made indicated, and the use is non-commercial. See: http://creativecommons.org/licenses/by-nc/4.0/.

ORCID iD

Satoshi Shinohara http://orcid.org/0000-0003-3124-1141

\section{REFERENCES}

1 Campbell S. Fetal macrosomia: a problem in need of a policy. Ultrasound Obstet Gynecol 2014;43:3-10.

2 Bukowski R, Hansen NI, Willinger M, et al. Fetal growth and risk of stillbirth: a population-based case-control study. PLoS Med 2014;11:e1001633.

3 Boulet SL, Alexander GR, Salihu HM, et al. Macrosomic births in the United States: determinants, outcomes, and proposed grades of risk. Am J Obstet Gynecol 2003;188:1372-8.

4 Sørensen HT, Sabroe S, Rothman KJ, et al. Relation between weight and length at birth and body mass index in young adulthood: cohort study. BMJ 1997;315:1137.

5 Seidman DS, Laor A, Gale R, et al. A longitudinal study of birth weight and being overweight in late adolescence. Am J Dis Child 1991;145:779-5.

6 Chiavaroli V, Giannini C, D'Adamo E, et al. Insulin resistance and oxidative stress in children born small and large for gestational age. Pediatrics 2009;124:695-702.

7 Jolly MC, Sebire NJ, Harris JP, et al. Risk factors for macrosomia and its clinical consequences: a study of 350,311 pregnancies. Eur $J$ Obstet Gynecol Reprod Biol 2003;111:9-14.

8 Heiskanen N, Raatikainen K, Heinonen S. Fetal macrosomia--a continuing obstetric challenge. Biol Neonate 2006;90:98-103. 
9 Vieira MC, McCowan LME, North RA, et al. Antenatal risk factors associated with neonatal morbidity in large-for-gestational-age infants: an international prospective cohort study. Acta Obstet Gynecol Scand 2018:97:1015-24.

10 Boulvain M, Senat M-V, Perrotin F, et al. Induction of labour versus expectant management for large-for-date fetuses: a randomised controlled trial. Lancet 2015;385:2600-5.

11 Kim SY, Sharma AJ, Sappenfield W, et al. Association of maternal body mass index, excessive weight gain, and gestational diabetes mellitus with large-for-gestational-age births. Obstet Gynecol 2014;123:737-44.

12 Ouzounian JG, Hernandez GD, Korst LM, et al. Pre-pregnancy weight and excess weight gain are risk factors for macrosomia in women with gestational diabetes. J Perinatol 2011;31:717-21.

13 Minakami H, Maeda T, Fujii T, et al. Guidelines for obstetrical practice in Japan: Japan Society of obstetrics and gynecology (JSOG) and Japan association of obstetricians and Gynecologists (JAOG) 2014 edition. J Obstet Gynaecol Res 2014;40:1469-99.

$14 \mathrm{Kc} \mathrm{K}$, Shakya S, Zhang H. Gestational diabetes mellitus and macrosomia: a literature review. Ann Nutr Metab 2015;66 (Suppl 2):14-20.

15 Homko CJ, Sivan E, Nyirjesy P, et al. The interrelationship between ethnicity and gestational diabetes in fetal macrosomia. Diabetes Care 1995;18:1442-5.

16 Li Y, Liu Q-F, Zhang D, et al. Weight gain in pregnancy, maternal age and gestational age in relation to fetal macrosomia. Clin Nutr Res 2015;4:104-9.

17 Tan PC, Ling LP, Omar SZ. The 50-g glucose challenge test and pregnancy outcome in a multiethnic Asian population at high risk for gestational diabetes. Int J Gynaecol Obstet 2009;105:50-5.

18 Yee LM, Cheng YW, Liddell J, et al. 50-Gram glucose challenge test: is it indicative of outcomes in women without gestational diabetes mellitus? J Matern Fetal Neonatal Med 2011;24:1102-6.

19 Gezer A, Esen F, Mutlu H, et al. Prognosis of patients with positive screening but negative diagnostic test for gestational diabetes. Arch Gynecol Obstet 2002;266:201-4.

20 Dudhbhai M, Lim L, Bombard A, et al. Characteristics of patients with abnormal glucose challenge test and normal oral glucose tolerance test results: comparison with normal and gestational diabetic patients. Am J Obstet Gynecol 2006;194:e42-5.

21 Grotegut CA, Tatineni H, Dandolu V, et al. Obstetric outcomes with a false-positive one-hour glucose challenge test by the CarpenterCoustan criteria. J Matern Fetal Neonatal Med 2008;21:315-20.

22 Boriboonhirunsarn D, Sunsaneevithayakul P. Relationship between $50-g$ glucose challenge test and large for gestational age infants among pregnant women without gestational diabetes. $J$ Obstet Gynaecol 2019:39:141-6.

23 Wendland EM, Torloni MR, Falavigna M, et al. Gestational diabetes and pregnancy outcomes--a systematic review of the World Health Organization (WHO) and the International Association of Diabetes in Pregnancy Study Groups (IADPSG) diagnostic criteria. BMC Pregnancy Childbirth 2012;12:12-23.

24 Itabashi K, Fujimura M, Kusuda S, et al. Introduction of new neonatal standard anthropometric measurements. Nihon Shonika Gakkai Zasshi 2010;114:1271-93.

25 Dalfrà MG, Pacini G, Parretti E, et al. Elevated insulin sensitivity and $\beta$-cell function during pregnancy in mothers of growth-restricted newborns. Am J Physiol Endocrinol Metab 2011;301:E25-30.

26 Catalano PM, Kirwan JP, Haugel-de Mouzon S, et al. Gestational diabetes and insulin resistance: role in short- and long-term implications for mother and fetus. J Nutr 2003;133:1674S-83.

27 Ørskou J, Kesmodel U, Henriksen TB, et al. An increasing proportion of infants weigh more than 4000 grams at birth. Acta Obstet Gynecol Scand 2001;80:931-6.

$28 \mathrm{Ng} \mathrm{S}-\mathrm{K}, \mathrm{Olog} \mathrm{A}$, Spinks AB, et al. Risk factors and obstetric complications of large for gestational age births with adjustments for community effects: results from a new cohort study. BMC Public Health 2010:10:460.

29 Ben-Haroush A, Yogev Y, Hod M. Fetal weight estimation in diabetic pregnancies and suspected fetal macrosomia. J Perinat Med 2004;32:113-21.

30 Pressman EK, Bienstock JL, Blakemore KJ, et al. Prediction of birth weight by ultrasound in the third trimester. Obstet Gynecol 2000;95:502-6.

31 Frick AP, Syngelaki A, Zheng M, et al. Prediction of large-forgestational-age neonates: screening by maternal factors and biomarkers in the three trimesters of pregnancy. Ultrasound Obstet Gynecol 2016;47:332-9.

32 Shinohara S, Uchida Y, Hirai M et al. Relationship between maternal hypoglycaemia and small-for-gestational-age infants according to maternal weight status: a retrospective cohort study in two hospitals. BMJ Open 2016;6:e013749.

33 Catalano PM, Obesity CPM. Obesity, insulin resistance, and pregnancy outcome. Reproduction 2010;140:365-71.

34 Ensenauer R, Gmach J, Nehring I, et al. Increased hemoglobin A(1c) in obese pregnant women after exclusion of gestational diabetes. Clin Chem 2012:58:1152-4.

35 Jaipaul JV, Newburn-Cook CV, O'Brien B, et al. Modifiable risk factors for term large for gestational age births. Health Care Women Int 2009;30:802-23. 